\title{
Strength of Mechanically Fastened Composite Joints
}

\author{
Fu-Kuo Chang, Richard A. SCOTT and GeORge S. SPRINGER \\ Department of Mechanical Engineering and Applied Mechanics \\ The University of Michigan \\ Ann Arbor, Michigan 48109
}

(Received July 14, 1982)

\begin{abstract}
A method is presented for predicting the failure strength and failure mode of mechanically fastened fiber reinforced composite laminates. The method includes two steps. First, the stress distribution in the laminate is calculated by the use of a finite element method. Second, the failure load and the failure mode are predicted by means of a proposed failure hypothesis together with Yamada's failure criterion. A computer code was developed which can be used to calculate the maximum load and the mode of failure of joints involving laminates with different ply orientations, different material properties, and different geometries. Results generated by the present method were compared to data and to existing analytical and numerical solutions. The results of the present method were found to agree well with those reported previously. Parametric studies were also performed to evaluate the effects of joint geometry and ply orientation on the failure strength and on the failure mode.
\end{abstract}

\section{INTRODUCTION}

A MONG THE MAJOR advantages of laminated composite structures over conventional metal structures are their comparatively high strength to weight and stiffness to weight ratios. As a result, fiber reinforced composite materials have been gaining wide application in aircraft and spacecraft construction. These applications require joining composites either to composites or to metals. Most commonly, joints are formed using mechanical fasteners. Therefore, suitable methods must be found to determine the failure strengths of mechanically fastened joints. A knowledge of the failure strength would help in selecting the appropriate joint size in a given application. 
Owing to the significance of the problem, several investigators have developed analytical procedures for calculating the strength of bolted joints in composite materials. Among recent studies are those of Waszczak and Cruse [1], Agarwal [2], Garbo and Ogonowski [3] and Wong and Matthews [4]. As will be discussed in Section VII, previous methods provide conservative results and underestimate the failure strength, often by as much as fifty percent. The major objective of this investigation was, therefore, to develop a method which a) predicts the failure strength and a failure mode of mechanically fastened composite plates with better accuracy than the existing analytical methods and b) can be used readily in the design of mechanically fastened composite joints.

An issue is whether a two or three dimensional stress analysis is required. If the stacking sequence is known to be important, then a three dimensional analysis, such as that used by Rybicki and Schmueser [5], must be employed. For open holes in glass-epoxy, boron-epoxy and graphite-epoxy laminates, Daniel, Rowlands and Whiteside [6] found that the stacking sequence did have a $10-20 \%$ effect on strength and could alter the failure mode. Whitney and Kim [7] however, showed that for quasi-isorropic graphite-epoxy laminates the notch strength was independent of the stacking sequence for notch sizes which caused tensile failure before delamination at the straight free edge. In experiments on pin-loaded holes in glass fiber reinforced plastic plates, Quinn and Matthews [8] showed that both the failure mode and the strength did indeed depend on the stacking sequence.

Wong and Matthews [4] used a two-dimensional finite element analysis to calculate stresses and strains in the bolted joint problem, arguing that it is known that when the laminate is constrained laterally by washers in bolt-loaded holes then the stacking sequence is unimportant. Based on such a two-dimensional analysis, they found a correspondence between the calculated strains and experimental data from tests on glass fiber reinforced epoxy resin.

It seems clear that to some degree three-dimensional effects are present, but they may not be critical. Weighing the available evidence, a two-dimensional finite element analysis was chosen for the present work. In addition to the lateral constraint argument, we were swayed also by the following facts. 1) The results obtained from the analysis are close to the experimental data, as will be shown below. 2) The stacking sequence, when important, seems to involve $10-20 \%$ effects, which would appear to be within the tolerances of the state of the art analyses. 3) The relative simplicity and inexpensiveness of a two-dimensional code over three-dimensional ones should make it an attractive design aid.

A second ingredient in the analysis is failure. Here the failure load and the failure mode are predicted by means of a new failure hypothesis together with Yamada's [9] failure criterion. Another remark regarding the stress analysis should be made here. Three dimensional effects are most significant near boundaries and interfaces, but the failure hypothesis adopted here involves stresses at some distance from the pin-hole interface.

The computer code which was developed can be applied to joints involving laminates with different ply orientations, different material properties, and dif- 
ferent configurations, including different hole sizes, hole positions and thicknesses.

\section{PROBLEM STATEMENT}

Consider a plate (length $L$, width $W$, thickness $H$ ) made of $N$ fiber reinforced unidirectional plies. The ply orientation is arbitrary, but must be symmetric with respect to the $x_{3}=0$ plane (see Figure 1). Perfect bonding between each ply is assumed.

A hole of diameter $D$ is located along the centerline of the plate $\left(x_{1}=0\right)$ at a distance $E$ from one end of the plate. A rigid pin (diameter $D$ ), supported outside the laminate, is inserted into the hole and a uniform tensile load $P$ is applied to the plate. The load is parallel to the plate and is symmetric with respect to the centerline. Hence the load cannot create bending moments about either the $x_{1}, x_{2}$ or $x_{3}$ axes. Moreover, for symmetric laminates, in-plane and bending effects are uncoupled. It is desired to find

1) the stresses and strains in each ply,

2) the maximum (failure) load $\left(P_{\max }\right)$ that can be applied before the joint fails, and

3) the mode of failure

Point 2 refers to the fact that, according to experimental evidence, mechanically fastened joints under tensile loads generally fail in three basic modes referred to as tension mode, shearout mode, and bearing mode. The type of damage resulting from each of these modes is illustrated in Figure 2. The objective listed in point 3 above, is to determine which of these modes will most be responsible for the failure.
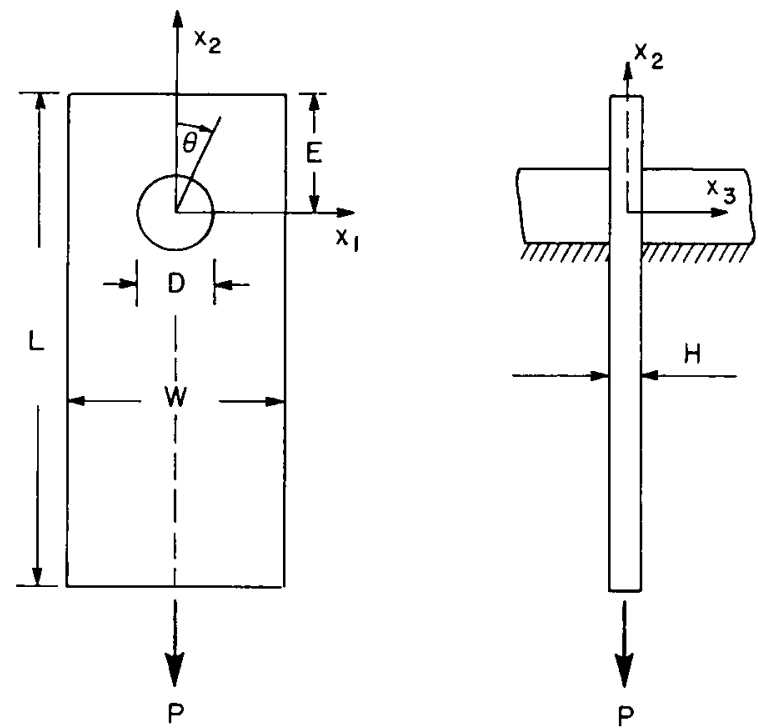

Figure 1. Geometry of the Problem. 


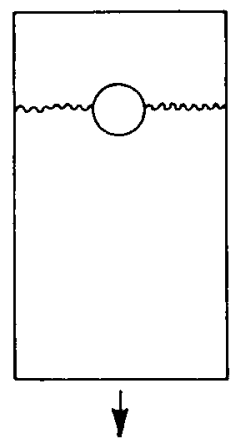

TENSION

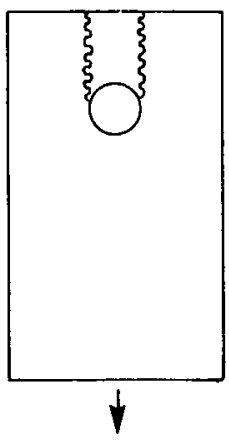

SHEAROUT

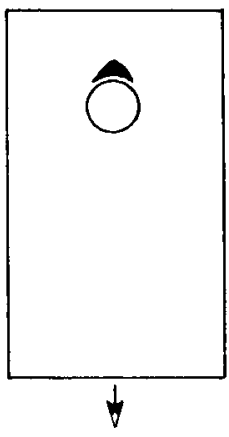

BEARING

Figure 2. Illustration of the Three Basic Failure Modes.

The calculation proceeds in three steps. For a given geometry and load

1) the stress distribution around the hole is calculated,

2) the maximum (failure) load is predicted, and

3) the mode of failure is determined.

The details of these steps are presented in Sections III-V.

\section{STRESS ANALYSIS-GOVERNING EQUATIONS}

The stresses in the laminate are calculated on the basis of anisotropic theory of elasticity and classical plate lamination theory. Accordingly, in the analysis, planes are taken to remain planes, the strain across the thickness is taken to be constant $\left[\varepsilon_{i j}=f\left(x_{1}, x_{2}\right)\right]$ and only plane stresses are considered $\left(\sigma_{13}=\sigma_{23}=\sigma_{33}\right.$ $=0$ ). Under these conditions, in the absence of body forces, force equilibrium can be expressed as [10]

$$
\sigma_{i j, j}=0
$$

The subscripts $i$ and $j$ may have the values 1 or 2 and the comma denotes differentiation w.r.t. $x_{j}$. Consider now an elastic laminate of volume $V_{o}$ containing a loaded hole as shown in Figure 3. Stresses are applied over the surface area $A_{L}$. The surface area $A_{R}$ is rigidly fixed (no displacement), while the surface area $A_{F}$ is free of applied stress. The total surface area is

$$
A=A_{L}+A_{R}+A_{F}
$$

Let us denote by $\bar{u}_{i}$ arbitrary displacements (test functions). The only requirement is that $\bar{u}_{i}$ be continuous, differentiable and be zero on $A_{R}$. By multiplying eq. (1) by $\bar{u}_{i}$ and taking the volume integral of the resulting expression we obtain

$$
\iiint_{V_{o}} \sigma_{i j, j} \bar{u}_{i} d V=0
$$



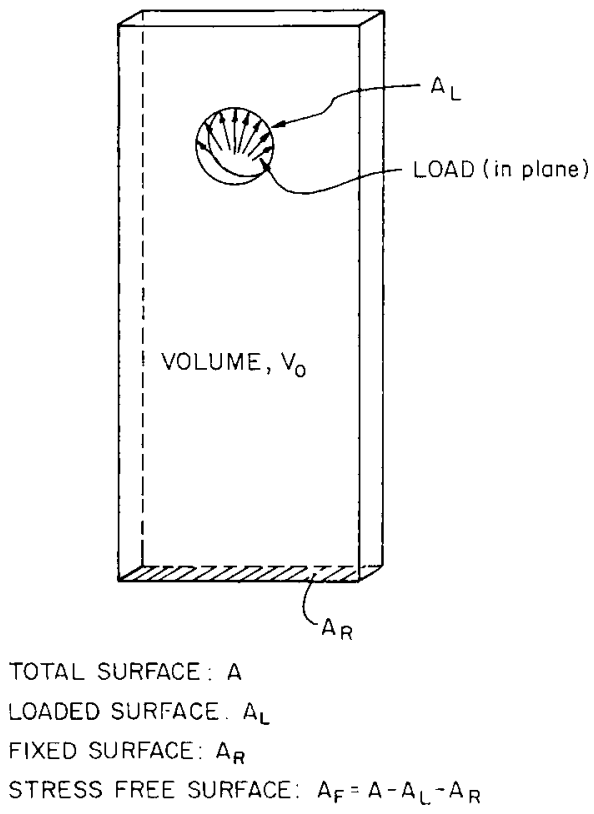

Figure 3. Configuration of an Elastic Laminate with a Loaded Hole.

Employing the identity

$$
\sigma_{i j, j} \overline{u_{i}}=\left(\sigma_{i j} \bar{u}_{\mathrm{i}}\right)_{, j}-\sigma_{i j} \bar{u}_{i, j}
$$

and utilizing Gauss' theorem, eq. (3) may be written as

$$
\iint_{A} \sigma_{i j} n_{j} \bar{u}_{i} d A-\iiint_{V_{O}} \sigma_{i j} \bar{u}_{i, j} d V=0
$$

On the free surface $A_{F}$ the stresses are zero, while on the surface $A_{R}$ the displacements are zero. These conditions give

$$
\begin{aligned}
& \iint_{A_{F}} \sigma_{i j} n_{j} \bar{u}_{i} d A=0 \\
& \iint_{A_{R}} \sigma_{i j} n_{j} \bar{u}_{j} d A=0
\end{aligned}
$$

The surface traction at each point on $A_{L}$ is given by [10]

$$
T_{i}=\sigma_{i j} n_{j}
$$


Equations (5)-(8) yield

$$
\iint_{A_{L}} T_{i} \overline{u_{i}} d A=\iiint_{V_{O}} \sigma_{i j} \bar{u}_{i, j} d V
$$

The stress-strain relationship for a linear elastic body is

$$
\sigma_{i j}=E_{i j k \ell} \epsilon_{k \ell}
$$

The subscripts $k$ and $\ell$ may take on the values of 1 or 2 . The strain displacement relations are

$$
\epsilon_{k \ell}=\frac{1}{2}\left(\frac{\partial u_{k}}{\partial x_{\ell}}+\frac{\partial u_{\ell}}{\partial x_{k}}\right)
$$

By combining eqs. (9)-(11) we obtain

$$
\iiint_{V_{O}} E_{i j k \ell} \bar{u}_{i, j} u_{k, \ell} d V=\iint_{A_{O}} T_{i} \bar{u}_{i} d A
$$

Because of the laminate symmetry, the following simplification may be made

$$
E_{i j k \ell} \equiv E_{m n}
$$

The subscripts $i, j, k$, and $\ell$ are related to $m$ and $n$ as follows

$$
\begin{aligned}
& i=j=1 \rightarrow m=1 \quad k=\ell=1 \rightarrow n=1 \\
& i=j=2 \rightarrow m=2 \quad k=\ell=2 \rightarrow n=2 \\
& i \neq j \quad \rightarrow m=3 \quad k \neq \ell \quad \rightarrow n=3
\end{aligned}
$$

The reduced laminate moduli $E_{m n}$ are given by

$$
E_{m n}=\sum_{p=1}^{N} \frac{h^{P}}{H} \bar{Q}_{i j}^{P}
$$

where $h^{p}$ is the thickness of the $p$-th and $Q_{i j}^{P}$ is the transformed reduced stiffness matrix for the $p$-th ply $[1,12]$.

\section{STRESS ANALYSIS-FINITE ELEMENT METHOD}

To perform the calculations, the problem illustrated in Figure 1 was simulated by the geometry given in Figure 4 . Because of symmetry the stresses were calculated only in one half of the body. Along the symmetry axis, displacement is allowed only in the $x_{2}$ direction. Along the lower edge of the plate, 


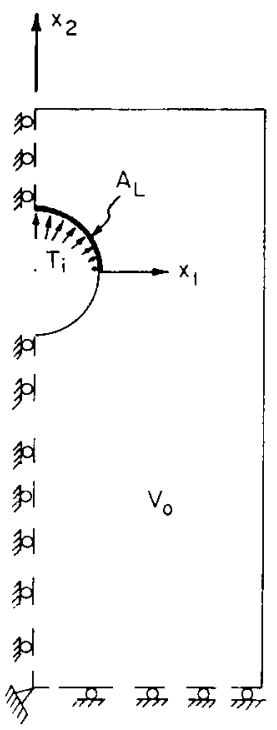

Figure 4. Configuration of a Joint Approximated in the Finite Element Method.

displacement is allowed only in the $x_{1}$ direction. The intersection of the symmetry axis and the lower edge is considered to be rigidly fixed.

The spatial distribution of the surface traction $T_{i}$ depends on the magnitude of the applied load, on the material properties, and on the geometry in a complex manner. It is extremely difficult to determine the exact distribution of $T_{i}$ inside the hole. To overcome this difficulty a cosine normal load distribution was assumed. With this approximation $T_{i}$ becomes

$$
T_{i}=-\frac{4 P}{\pi D} n_{i} \cos \theta
$$

The angle $\theta$ is in the $x_{1}-x_{2}$ plane and is measured clockwise from the $x_{2}$ axis (Figure 1). For isotropic materials the cosine normal load distribution (eq. 16) was found to represent closely the actual load distribution [13]. Wong and Matthews [4] also used a trigonometric distribution. Calculations performed by previous investigators also showed that for composite materials the stress distribution inside (in contrast to on boundaries) the body is insensitive to the assumed load distribution $[1,3,14]$. Therefore, eq. (16) should suffice for the purpose of the present analysis which is to determine the overall strength of the joint.

Equations (12) and (16) give, noting that in two-dimensions volume and area integrals reduce to area and line integrals, respectively,

$$
\iint_{S} E_{i j k \ell} \bar{u}_{i, j} u_{k, \ell} d s=\int_{\Gamma_{L}}-\frac{4 P}{\pi D} n_{i} \bar{u}_{i} \cos \theta d \Gamma
$$




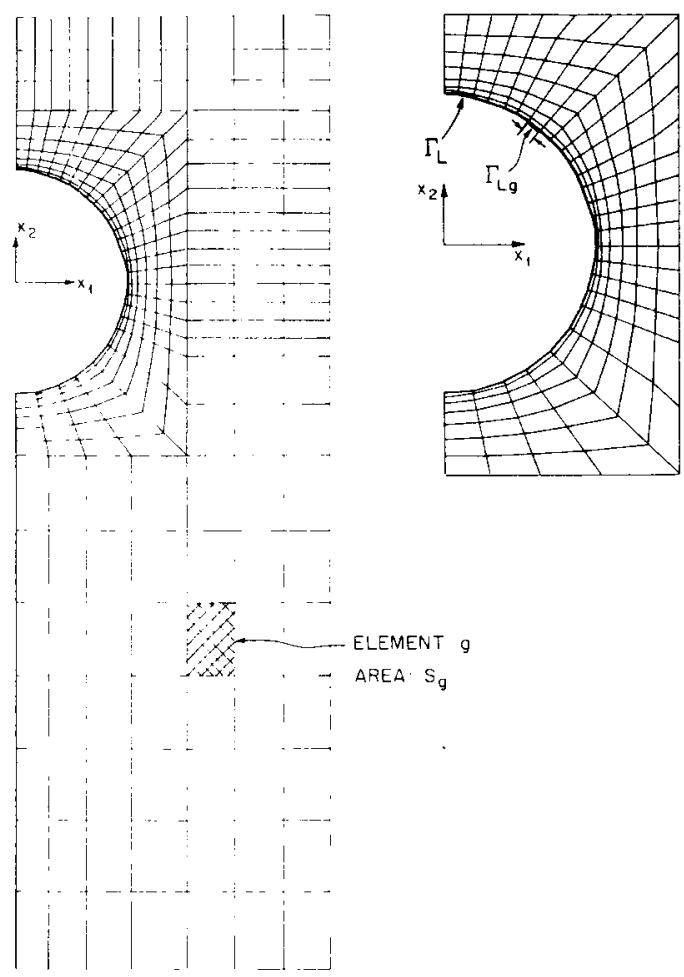

Figure 5. Grid Used in the Finite Element Method. Right Hand Figure is an Enlarged View of the Grid Around the Hole.

Solutions to eq. (17) were obtained by a finite element method. Isoparametric four-node elements were used. The grid sizes were unequal. Smaller grids were used in the vicinity of the hole to obtain a better resolution of the stresses. Utilizing the symmetry about the $x_{2}$ axis, a grid (consisting of 306 elements) was placed on one half of the laminate, as illustrated in Figure 5 .

The displacements in each element can be expressed in terms of the displacements of the four nodal points [15]

$$
u_{i}=N_{\alpha} q_{i \alpha}
$$

The subscript $\alpha$ designates the nodal points ( $\alpha=1,2,3$, or 4$). N_{\alpha}$ is the shape function described in detail in Ref. [12]. $q_{i_{\alpha}}$ is the displacement at the nodal point $\alpha$ in the $i$ direction.

We define a stiffness matrix for the $g$-th element as

$$
K_{i \beta k \alpha}^{g} \equiv \iint_{S_{g}} E_{i j k \ell} N_{\alpha, \ell} N_{\beta, j} d s
$$


$K_{i \beta k \alpha}^{g}$ is an eight by eight matrix. The subscript $\beta$ may take on the values $1,2,3$, and 4. Accordingly, eqs. (17), (18) and (19) yield,

$$
\sum_{g=1}^{M} K_{i \beta k \alpha}^{g} q_{k \alpha} \bar{q}_{i \beta}=\sum_{g=1}^{M} \bar{q}_{i \beta} \int_{\Gamma_{L g}}-\frac{4 P}{\pi D} n_{i} N_{\beta} \cos \theta d \Gamma
$$

where $\Gamma_{L g}$ are segments of the hole boundary on which the forces are applied.

The functions $q_{i \beta}$ are arbitrary functions and hence eq. (23) can be written

$$
\bar{K}_{i \beta k \alpha} q_{k \alpha}=\bar{F}_{i \beta}
$$

where the global stiffness matrix, $\bar{K}_{i \beta k a}$ and the load vector $\bar{F}_{i \beta}$ are given by

$$
\begin{gathered}
\bar{K}_{i \beta k \alpha} \equiv \sum_{g=1}^{M} K_{i \beta k \alpha}^{g} \\
\bar{F}_{i \beta} \equiv \sum_{g=1}^{M} \int_{\Gamma_{L g}}-\frac{4 P}{\pi D} n_{i} N_{\beta} \cos \theta d \Gamma
\end{gathered}
$$

The elements of $\bar{K}_{i \beta k a}$ and the components of the vector $\bar{F}_{i \beta}$ are known. Hence, $q_{k \alpha}$ can be obtained from eq. (21) using the Gaussian elimination method. Once $q_{k a}$ are known the displacements $u_{i}$ are calculated from eq. (21). Then the stresses and strains can be calculated from eqs. (10) and (11).

\section{PREDICTION OF FAILURE}

To determine the load at which a joint fails and the mode of failure, the conditions for failure must be established. In this investigation the joint is taken to have failed when the combined stresses have exceeded a prescribed limit in any of the plies along an approximately chosen curve (denoted as the characteristic curve). The combined stress limit is evaluated using the failure criterion proposed by Yamada [9]. The coordinates of the characteristic curve are established by extending Whitney and Nuismer's failure hypothesis [16] (developed for open, unloaded holes) to loaded holes.

\section{1) Failure Criterion}

Numerous criteria for failure have been proposed in the past $[17,18,19,20]$. Although the concepts underlying the different failure criteria may be different, the results of the various criteria are generally quite similar. Here Yamada's failure criterion is adopted [9]. This criterion is based on the assumption that just prior to failure of the laminate every ply has failed due to cracks along the fibers. It states that failure occurs when the following condition is met in any one of the plies 


$$
\left(\frac{\sigma_{x}}{X}\right)^{2}+\left(\frac{\sigma_{x y}}{S_{c}}\right)^{2}=e^{2}\left\{\begin{array}{l}
e<1 \text { no failure } \\
e \geqq 1 \text { failure }
\end{array}\right.
$$

$\sigma_{x}$ and $\sigma_{x y}$ are the longitudinal and shear stresses in a ply, respectively ( $x$ and $y$ being the coordinates parallel and normal to the fibers in the ply). $X$ is the longitudinal tensile strength of the ply. $S_{c}$ is the shear strength of a symmetric, cross ply laminate which has the same number of plies as the laminate under consideration. As indicated in eq. (24) failure occurs when $e$ is equal to or greater than unity.

\section{2) Failure Hypothesis-Characteristic Curve}

Here we propose that failure occurs when in any one of the plies the combined stresses satisfy an appropriately chosen failure criterion at any point on a characteristic curve. The characteristic curve (Figure 6) is specified by the expression

$$
r_{c}(\theta)=D / 2+R_{o t}+\left(R_{o c}-R_{o t}\right) \cos \theta,-\frac{\pi}{2} \leq \theta \leq \frac{\pi}{2}
$$

$R_{o t}$ and $R_{o c}$ are the characteristic lengths for tension and compression [16,21]. These parameters can be determined experimentally by measuring the tensile and compressive strengths of notched laminates. $R_{o t}$ and $R_{o c}$ depend only on the material. Therefore, the coordinates of the characteristic curve also depend only on the material, and are independent of the geometry and the stress distribution.

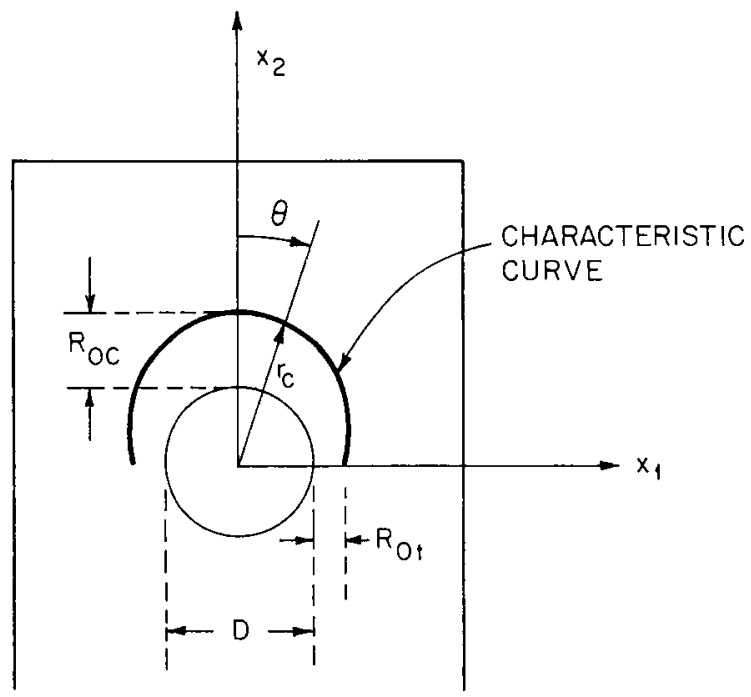

Figure 6. Description of the Characteristic Curve. 
In this investigation the characteristic curve is used together with the Yamada failure criterion. Accordingly (see eq. 24), failure occurs when the parameter $e$ is equal to or is greater than unity at any point on the characteristic curve

$$
\left.\begin{array}{ll}
\text { No failure } & e<1 \\
\text { Failure } & e \geq 1
\end{array}\right\} \text { at } r=r_{c}
$$

It should be emphasized that the above failure hypothesis is used here in conjunction with the Yamada failure criteron. However, the hypothesis is general, and is not restricted to Yamada's criterion. The characteristic curve proposed here may be used with any other failure criterion.

\section{3) Solution Procedure}

Whether or not a joint fails under a given condition is determined as follows. For a given load

a) the stresses $\left(\sigma_{1}, \sigma_{2}, \sigma_{12}\right)$ are calculated in each ply using the finite element method described in Sections II, and III,

b) the longitudinal and shear stresses $\left(\sigma_{x}, \sigma_{x y}\right)$ are evaluated in each ply employing the transformations

$$
\begin{aligned}
\sigma_{x} & =\sigma_{1} \cos ^{2} \eta+\sigma_{2} \sin ^{2} \eta+2 \sigma_{12} \sin \eta \cos \eta \\
\sigma_{x y} & =-\sigma_{1} \sin \eta \cos \eta+\sigma_{2} \sin \eta \cos \eta+\sigma_{12}\left(\cos ^{2} \eta-\sin ^{2} \eta\right)
\end{aligned}
$$

where $\eta$ is the angle measured counter clockwise from the $x_{1}$-axis to the $x$-axis of each ply.

c) the parameter $e$ is calculated (24) along the characteristic curve

d) if $e$ equals or exceeds the value of unity $(e \geqslant 1)$ in any ply along the characteristic curve, the joint is taken to have failed.

The procedure outlined above is used to predict whether or not failure occurs under a given load. Due to the assumption of a cosine normal load distribution around the hold (eq. 16), the calculated stresses are linearly proportional to the applied load $P$. This fact together with Yamada's failure criterion gives

$$
P \sim e
$$

The relationship is utilized to determine the maximum load $\left(P_{\max }\right)$ which can be imposed on the joint. For a given load $P$, values of $e$ are calculated on the characteristic curve as discussed above (points a-d). The highest value of $e\left(e_{0}\right)$ is determined, and the maximum load is calculated by the expression

$$
P_{\max }=\frac{P}{e_{o}}
$$


so when $P=P_{\max }, e_{o}=1$.

The calculation procedure described in the foregoing also provides the location (angle $\theta_{f}$ ) at which $e$ first reaches the value of unity on the characteristic curve. (Figure 7). A knowledge of $\theta_{f}$ provides an estimate of the mode of failure. When $\theta_{f}$ is small $\left(\theta_{f} \approx 0^{\circ}\right)$ failure is by the bearing mode. When $\theta_{f} \approx 45^{\circ}$ failure is due to shearout. When $\theta_{f} \approx 90^{\circ}$ failure is caused by tension. In summary, we take

$$
\begin{aligned}
-15^{\circ} & <\theta_{f}<15^{\circ} \rightarrow \text { bearing mode } \\
30^{\circ} & <\theta_{f}<60^{\circ} \rightarrow \text { shearout mode } \\
75^{\circ} & <\theta_{f}<90^{\circ} \rightarrow \text { tension mode }
\end{aligned}
$$

At intermediate values of $\theta_{f}$ failure may be caused by a combination of these modes.

\section{NUMERICAL SOLUTION}

A computer code (designated as BOLT) was developed which is suitable for generating solutions to the problem formulated in Sections II-V. The required input parameters and the output provided by the code are summarized in Table 1.

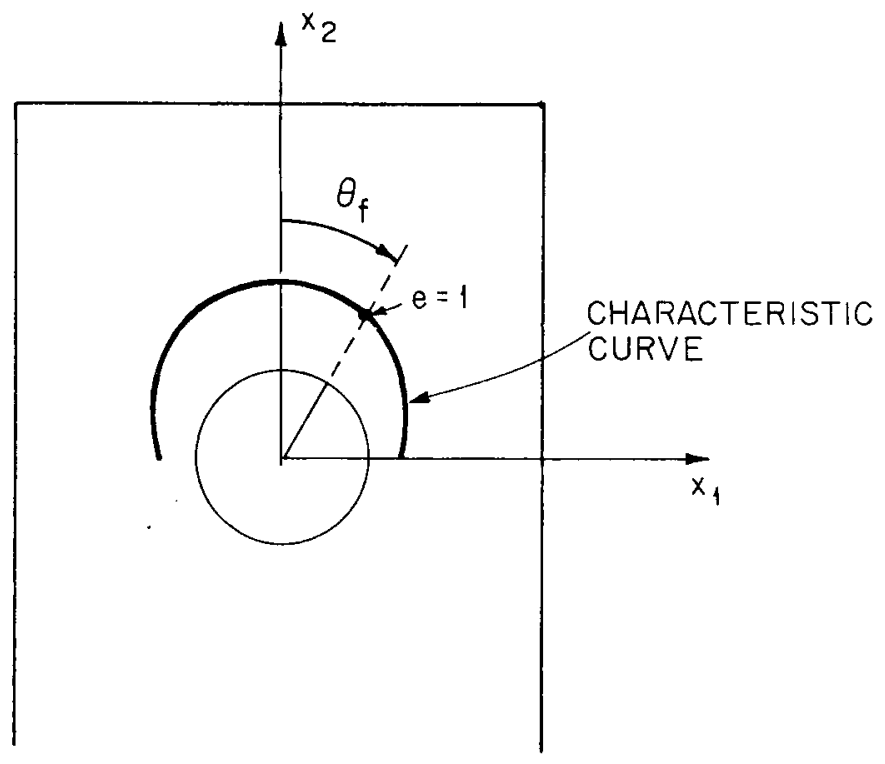

Figure 7. Location of Failure (e $=1)$ along the Characteristic Curve. 
Table 1. Input Parameters Required

by the Computer Code and the Output Provided by the Code

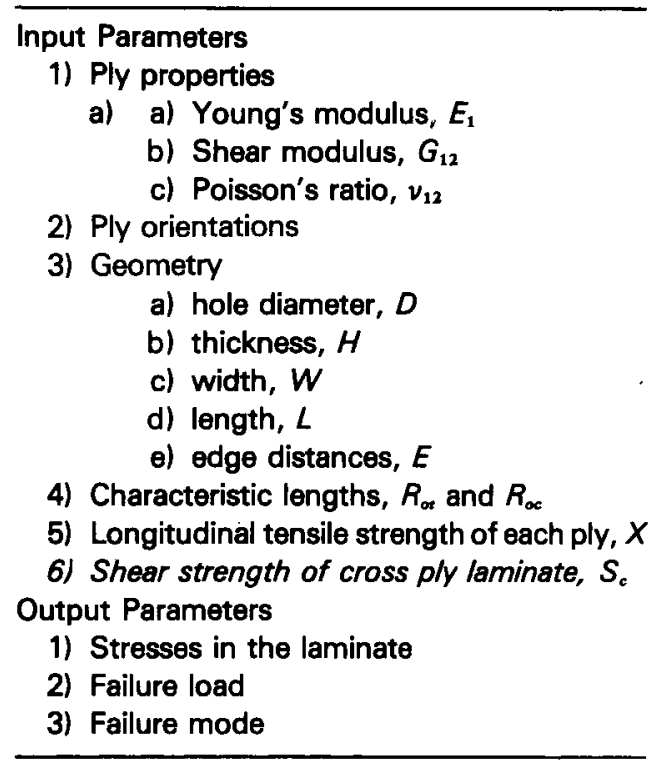

A Fortran listing of the code and a sample input-output may be obtained from the Department of Mechanical Engineering and Applied Mechanics, the University of Michigan, Ann Arbor, Michigan.

\section{RESULTS AND DISCUSSIONS}

Results were generated to assess the validity and accuracy of the method and the computer code. In addition, parametric studies were performed to evaluate the major characteristics of bolted joints.

\section{1) Isotropic and Orthotropic Plates}

Stress distributions were calculated in isotropic plates containing both unloaded (open) and loaded holes and in orthotropic plates containing unloaded holes. These problems were selected because analytical solutions are available for comparisons with the results of the present method.

An analytical solution for the stress distribution in an infinite $(W \rightarrow \infty)$ isotropic plate containing an unloaded hole was given by Timoshenko [22]. The stress distribution in such a plate was also calculated by the present method. The parameters used in the numerical calculations are given in Figure 8. A large width $(W / D=14)$ was used in the calculation to approximate an infinite plate. The results of the present method and the analytical solution of Timoshenko are 


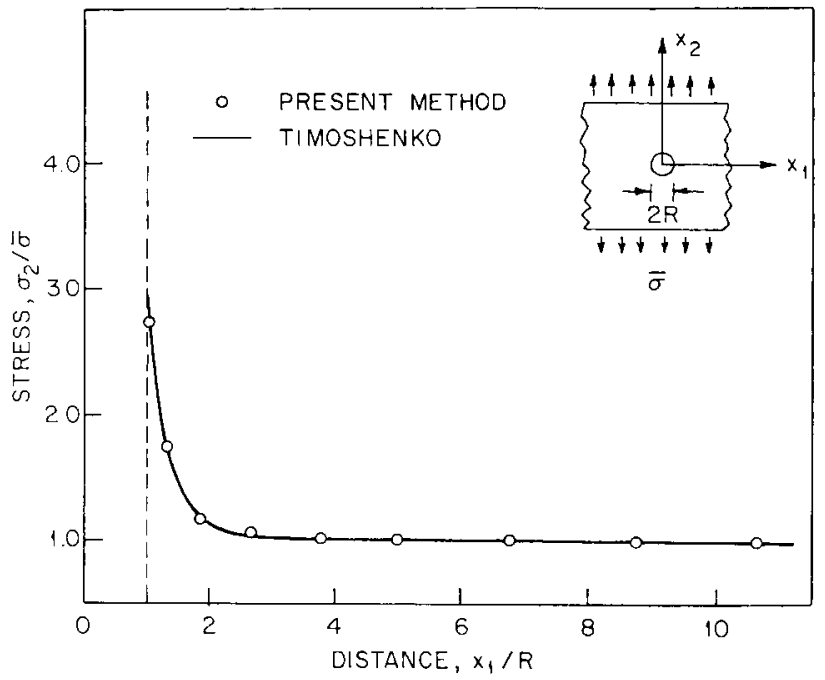

Figure 8. The Stress $\sigma_{2}$ along the $x_{1}$-axis in an Isotropic Infinite Plate Containing a Circular Hole. Comparison of the Present Results with the Theoretical Results Given by Timoshenko.[22] Parameters used in the Numerical Calculatons: $\sigma=1.64 \mathrm{MPa}, D=2 R=7.62 \mathrm{~mm}, W / D=14$, $E / D=14, L / D=28$.

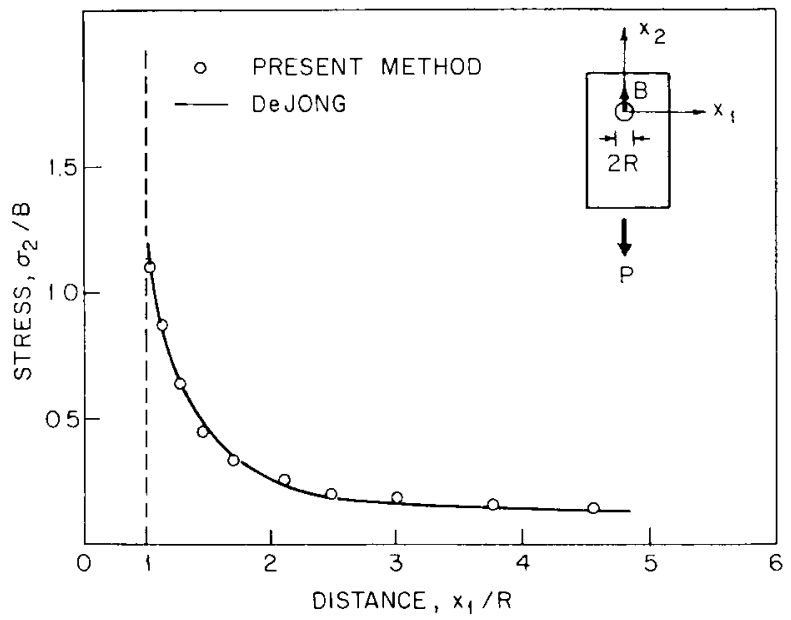

Figure 9. The Stress $o_{2}$ along the $x_{1}$-axis in an Isotropic Plate of Finite Width Containing a Loaded Hole. Comparison of the Present Results with the Theoretical Results Given by De Jong [14]. Parameters Used in the Numerical Calculations: $D=7.62 \mathrm{~mm}, W / D=5.0, E / D=4.0$, $L / D=14.0$. 
compared in Figure 8. There is excellent agreement between the stresses calculated by the two methods.

The stresses in isotropic plates containing loaded holes were also calculated. Plates of infinite and finite widths were considered. Calculations were performed for the parameters given in Figure 9 and Table 2. From the calculated stresses, the stress concentration factor was determined. The stress concentration factor is defined as

$$
S C F \equiv \frac{\left(\sigma_{2}\right)_{\max }}{B}
$$

where $\left(\sigma_{2}\right)_{\max }$ is the maximum stress in the plate and $B$ is the bearing stress defined by

$$
B \equiv \frac{P}{(H)(D)}
$$

The stress concentration factors obtained by the present method were compared to those reported by previous investigators (Table 2). The maximum difference in the stress concentration factors given by the different methods is about 20 percent. The stress concentration factor given by the present method differs from the values given by previous investigators at most by 15 percent.

The stresses in an isotropic plate of finite width containing a loaded hole are shown in Figure 9. The stresses calculated by the present method are in excellent agreement with De Jong's approximate solution [14].

The stress distribution in an orthotropic plate of finite width containing an open (unloaded) hole was also calculated. The calculations were performed for a plate with the symmetric laminate lay up of $[0 / 90]_{\mathrm{s}}$. An analytical solution for this problem was provided previously by Nuismer and Whitney [21], who modified Lekhnitskii's earlier solution [23] for an infinite plate. The results

Table 2. Stross Concentration Factor (SCF) Around a Pin Loaded Holo in an Isotropic Plate of Infinite Width. Comparison of Present Result with Those Obtained by Provious Investigators.

\begin{tabular}{ll}
\hline Investigators & SCF \\
\hline Present Result* & 0.985 \\
Hong [25] & 0.955 \\
De Jong [14] & 1.058 \\
Eshwar et al. [26] & 0.922 \\
Bickley [13] & 0.81 \\
\hline
\end{tabular}

* Present results were calculated for the case: $D=7.62 \mathrm{~mm}$ (0.37, $W / D=8, E / D=4, L / D=14$. 
given in Figure 10 show excellent agreement between the stresses calculated by the present method and by the analytical solution.

The aforementioned comparisons indicate that the present method predicts the stress distribution around loaded and unloaded holes with high accuracy.

\section{2) Failure Strength and Failure Mode}

Failure strengths of mechanically fastened composite joints calculated by the present method were compared to available data and to failure strengths predicted by other numerical methods.

Failure strengths of joints in two graphite-epoxy laminates were measured by Van Siclen [24] and by Garbo and Ognowski [3]. The test conditions are summarized in Table 3. The failure strengths of the joints under these conditions were also calculated by the present method. The values used for the material properties $S_{c}, R_{o t}, R_{o r}$, will now be discussed. Tests done by Yamada [9] on glass/epoxy laminates showed that the laminate shear strength $S_{c}$ of a $0.762 \mathrm{~mm}$ $(0.03$ ") thick specimen is two to three times higher than the lamina shear strength. For Graphite/Epoxy T300/SP $286\left(0.04\right.$ ") reported upon here, $S_{c}$ was taken to be 2.5 times the shear strength $S$ given by Van Siclen [24]. Since the thickness of AS/3501 laminate was $5.28 \mathrm{~mm}\left(0.208^{\prime \prime}\right)$ thick, a multiplier of 1.7

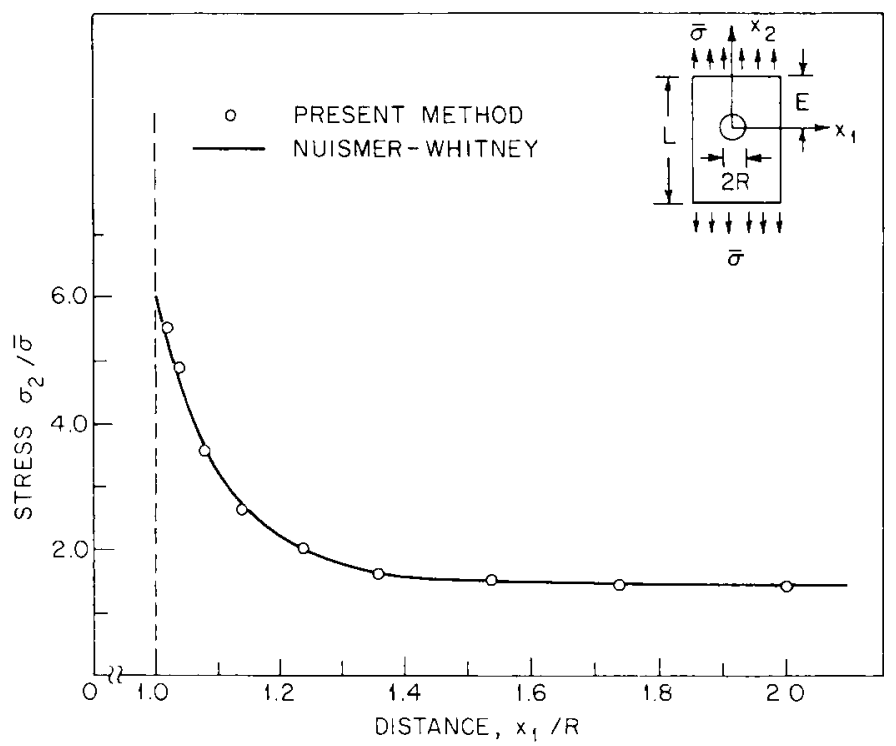

Figure 10. The Stress $o_{2}$ along the $x_{1}$-axis in an Orthotropic Finite Plate $[0 / 90]_{5}$ Containing a Circular Hole. Comparison of the Present Results with the Theoretical Results Obtained by Nuismer and Whitney [21]. Parameters Used in the Numerical Calclations: material: Graphite/Epoxy T300/ $5208, E_{1}=149.8 \mathrm{GPA}, E_{2}=G P a, G_{12}=5.39 \mathrm{GPa}, v_{23}=0.29, \quad o=2.3 \mathrm{MPa}, D=24.5 \mathrm{~mm}$, $W / D=3.0, E / D=4.0, L / D=14.0$. 


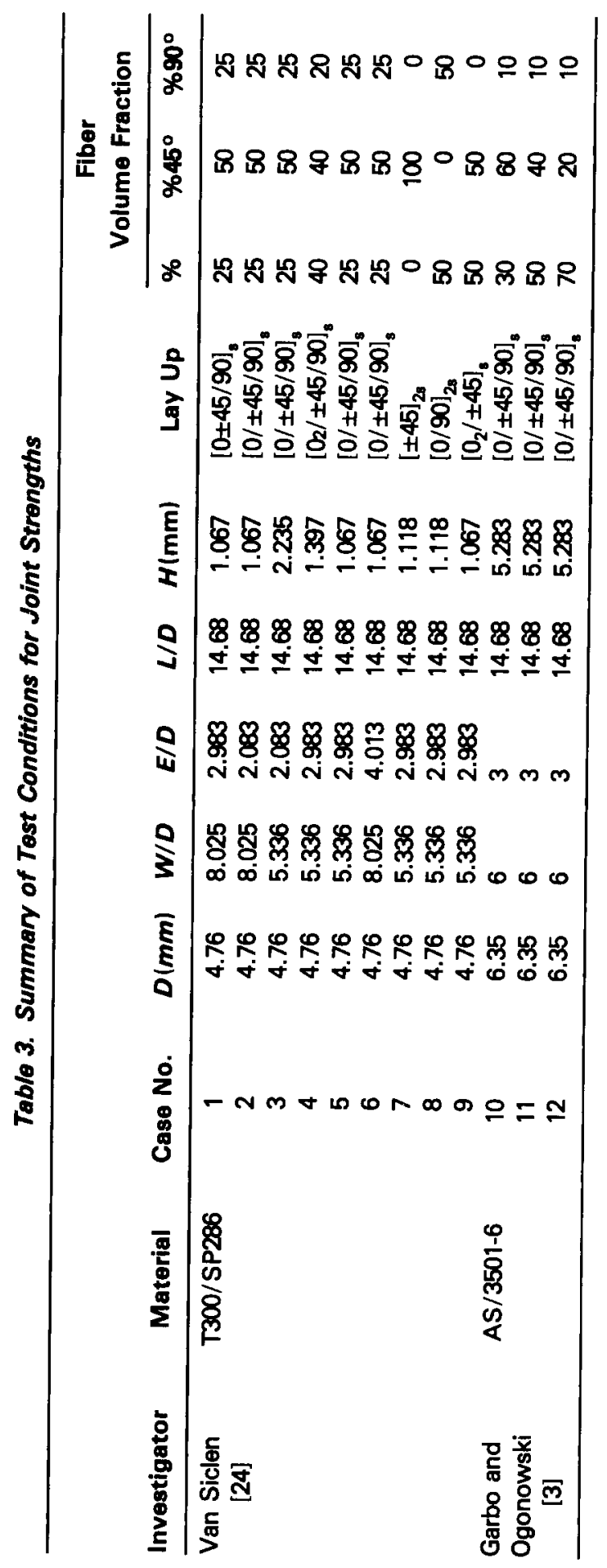


was used and good results were obtained. The factor of 2.5 was also tried for the AS/3501 laminate. It was found that the results differed by less than $5 \%$ from the above predictions. It is worthy to note here that in our experience, the predicted strength is insensitive to the value of $S_{c}$ except for laminates having over $70 \%$ unidirectional fibers in the loading direction.

Nuismer and Whitney [21] determined experimentally $R_{o c}=1.092 \mathrm{~mm}$ $(0.043$ ") for Graphite/Epoxy T300/5208. Even though the material used here is T300/SP286, the same value of $R_{o t}=1.092 \mathrm{~mm}$ was used. For AS/3501-6, Garbo and Ogonowski [3] reported a range of experimental values for $R_{o t}$ between $0.457 \mathrm{~mm}\left(0.018^{\prime \prime}\right)$ and $0.609 \mathrm{~mm}\left(0.024^{\prime \prime}\right)$. A value of $0.584 \mathrm{~mm}\left(0.023^{\prime \prime}\right)$ was used in this report.

No direct measurements of $R_{o c}$ are available. Values for this parameter were estimated as follows. Nuismer and Labor [27] reported data for a related parameter $A_{o c}$ for AS/3501-5. This parameter enters into the "average stress criterion" defined by Nuismer and Whitney [16]. The value of $R_{o c}$ for AS/3501-5 was determined using the $A_{o c}$ value given in Ref. [27] and eqs. (5) and (8) of Ref. [21]. This value of $R_{o c}$ was used here for AS/3501-6. For T300/SP286 the value of $R_{o c}$ was determined as follows. A value of the $A_{o t}(=0.15$ ") was reported by Nuismer and Whitney [21] for T300/5208. Furthermore, Nuismer and Labor (27) found the ratio $A_{o c} / A_{o t}$ for AS/3501-5 to be 2.7. Using this ratio, and the value $A_{o t}\left(0.15^{\prime \prime}\right)$ the parameter $A_{o c}$ was calculated $\left(A_{o c}=0.405\right.$ "). From the known value of $A_{o c}$ the parameter $R_{o c}$ was then calculated by the procedure outlined above for AS/3501-6. The material properties used in the calculations are listed in Table 4.

Comparisons between the experimental and predicted failure strengths are given in Table 5. In these tables comparisons between the data and the failure

Table 4. Material Properties Used in the Calculations

\begin{tabular}{|c|c|c|}
\hline Ply Properties & T300/SP286 & AS/3501-6 \\
\hline Longitudinal Modulus $E_{1}$ Gpa (103 ksi) & $130(18.7)[2]$ & $130(18.85)[3]$ \\
\hline Transverse Modulus $E_{2} \mathrm{Gpa}\left(10^{3} \mathrm{ksi}\right)$ & $8.274(1.2)[2]$ & 13.1(1.9)[3] \\
\hline Shear Modulus $G_{12}$ Gpa $\left(10^{3} \mathrm{ksi}\right)$ & $5.033(0.73)[2]$ & $5.86(0.85)[3]$ \\
\hline Poisson Ratio $v_{12}$ & $0.30[2]$ & $0.30[3]$ \\
\hline Tensile Strength $X \mathrm{Gpa}\left(10^{3} \mathrm{ksi}\right)$ & $1.23(0.178)[2]$ & $1.58(0.23)[3]$ \\
\hline Shear Strength $S$ Gpa (103 ksi) & $0.05(0.0073)[2]$ & $0.12(0.017)[3]$ \\
\hline Laminate Properties & T300/SP286 & AS/3501-6 \\
\hline Cross-ply Laminate Shear & & $0.204(0.03)$ \\
\hline Strength $S_{c}$ Gpa (103 ksi) & $0.125(0.018)$ & $0.12^{(a)}(0.017)$ \\
\hline Characteristic Length $R_{o t} \mathrm{~mm}$ (in) & $1.092(0.043)$ & $0.584(0.023)[3]$ \\
\hline Characteristic Length $R_{o c} \mathrm{~mm}$ (in) & $3.048(0.12)$ & $1.727(0.068)$ \\
\hline
\end{tabular}

(a)This value was used for laminates containing more than $70 \%$ (by volume) of 0 degree plies. 
Table 5. Comparisons Between the Experimental (P) and Calculated (P.) Failure Loads. Case Numbers Correspond to Tast Conditions Given in Table 3.

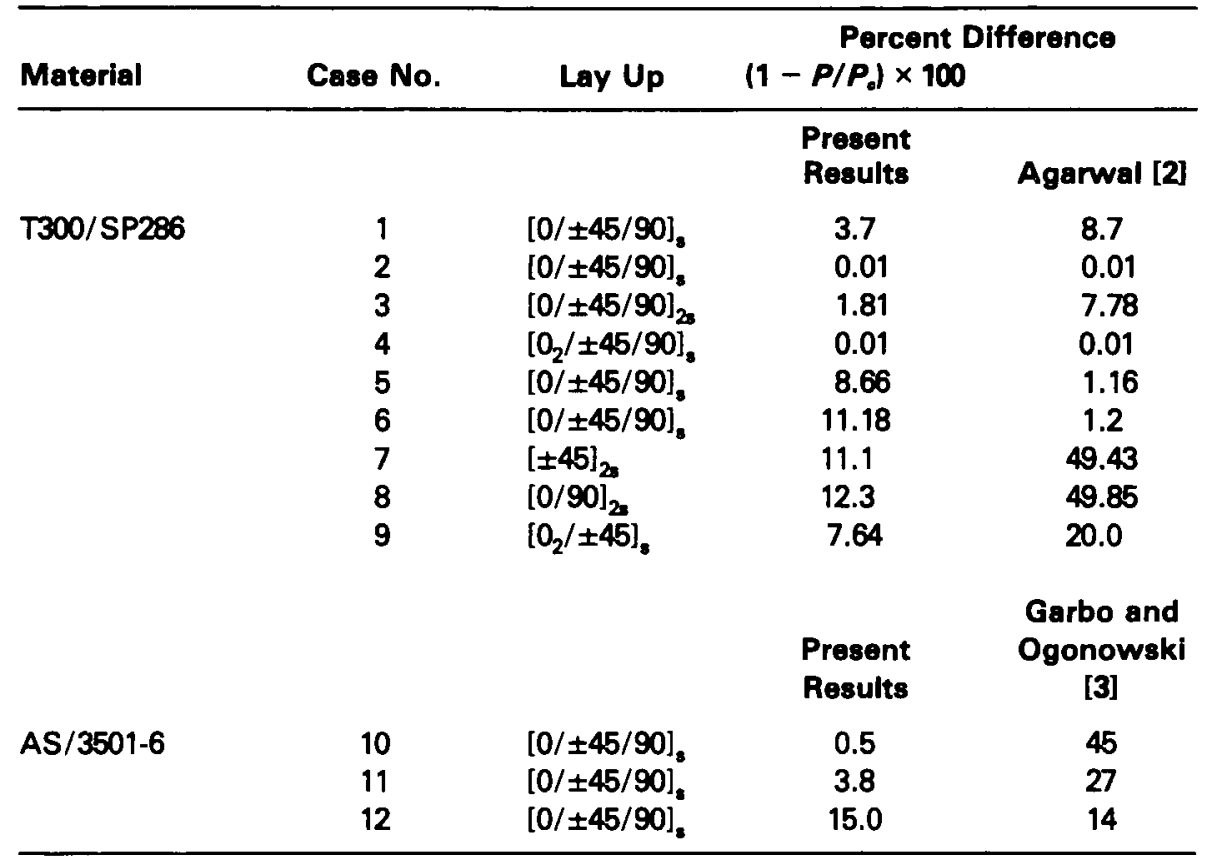

strengths predicted by Agarwal [2] and by Garbo and Ogonowski [3] are also included.

As can be seen, of the three analytical methods in general the present one predicts the failure most accurately. In most cases, the failure load given by the present method agrees with the data within about $10 \%$. On the other hand, the failure loads given by the Agarwal and by the Garbo and Ogonowski method can be in error by as much as 50 percent.

One point is of interest here. When there is a high fraction of zero degree plies in the laminate the laminate fails in the shearout mode. In this case the calculated results are sensitive to the value of the laminate shear strength $S_{c}$ For example, when the $S_{c}$ value obtained with cross ply laminates is used to calculate the failure load of $[0 / \pm 45 / 90]_{s}$ laminates containing 70 percent of $0^{\circ}$ plies the calculated and measured values differed by 35 percent. On the other hand, if the shear stress of the individual ply is used in the calculations the difference between the calculated failure load and the data is only 15 percent.

Failure loads calculated by Waszczak and Cruse [1] are compared to data in Table 6. Waszczak and Cruse's method also yields failure loads which are in error by as much as 50 percent. The present method was not applied to Waszczak and Cruse's data because the material properties needed for the calculation were unavailable. 
Table 6. Comparisons Between Experimental Fallure Loads and the Values Predicted by Waszczak and Cruse [1]

\begin{tabular}{|c|c|c|c|c|c|c|c|}
\hline \multirow[b]{2}{*}{ Material } & \multirow[b]{2}{*}{ Lay Up } & \multicolumn{5}{|c|}{$\begin{array}{c}\text { Fiber } \\
\text { Volume Fraction \% }\end{array}$} & \multirow{2}{*}{$\begin{array}{c}\text { Percent } \\
\text { Difference } \\
\left(1-P / P_{c}\right) \\
\times 100\end{array}$} \\
\hline & & 45 & $\mathbf{0}$ & 90 & $W / D$ & $E / D$ & \\
\hline Graphite/Epoxy & {$[ \pm 45]$} & 100 & 0 & 0 & 4 & 3 & 53 \\
\hline \multirow[t]{5}{*}{ Boron/Epoxy } & {$\left[( \pm 45 / 0)_{\mathrm{g}} / 90\right]_{\mathrm{g}}$} & 72.3 & 18.2 & 9.1 & 4 & 2 & 24 \\
\hline & {$\left[ \pm 45_{5} / 90_{6}^{\circ}\right]$} & 62.5 & 0 & 37.5 & 4 & 3 & 7 \\
\hline & {$\left[ \pm 45 /\left(0_{6} / 90\right)_{8}\right]_{8}$} & 13.3 & 80.0 & 6.7 & 6 & 6 & 42 \\
\hline & {$\left[0_{6} / \pm 45_{5}\right]$} & 62.5 & 37.5 & 0 & 7.5 & 2.5 & 2 \\
\hline & {$\left[0_{6} / \pm 45\right]$} & 62.5 & 37.5 & 0 & 7.35 & 4 & 35 \\
\hline
\end{tabular}

It is interesting to note that the accuracies of all four methods (present, Agarwal, Garbo and Ogonowski, and Waszczak and Cruse) depend on the arrangements of the plies in the laminate. In general, the analytical predictions are most accurate for quasi-isotropic laminates $\left([0 / \pm 45 / 90]_{s}\right.$; equal volume fractions) and are least accurate for angle ply and cross ply laminates. However, even for angle ply and cross ply laminates the present method yields results within about 10 percent accuracy, in contrast with the results of other existing methods of solutions, which may be in error by as much as $\mathbf{5 0}$ percent.

The failure modes predicted by the present method were also compared to failure modes observed experimentally. These comparisons, given in Table 7 , show that the present method predicts well the mode of failure.

The aforementioned comparisons between the results of the present method and the data show that the method predicts with good accuracy both the load at which the joint fails and the mode of failure, thus creating confidence in the method. One final remark should be made here and that is on the form of the characteristic curve (eq. (25)). As a "sensitivity" study, we also tried elliptical and straight line forms. We found that strength prediction based on the ellipse differed by as much as $40 \%$ from the experimental data and also the predicted failure mode was incorrect. The straight line form led to even more serious errors.

\section{3) Effects of Geometry and Ply Orientations}

Parametric studies were performed to evaluate the effects of joint geometry and ply orientation on the failure strength and on the failure mode.

The effects of joint width on joint failure is illustrated in Figure 11. In this, and in subsequent figures, the failure load is normalized with respect to the ultimate tensile load of the laminate in the direction of the applied load. As is shown by the results in Figure 11, in general, the maximum load the joint can carry decreases as the hole size decreases, when the width to hole diameter ratio is greater than about 3 . As the hole diameter approaches the width $(W / D \rightarrow 1)$ 
Fu-Kuo Chang, Richard A. Scott and George S. Springer

Table 7. Comparisons of Predicted Failure Modes with those Observed Experimentally, T-Tension Mode, S-Shearout Mode, B-Bearing Mode

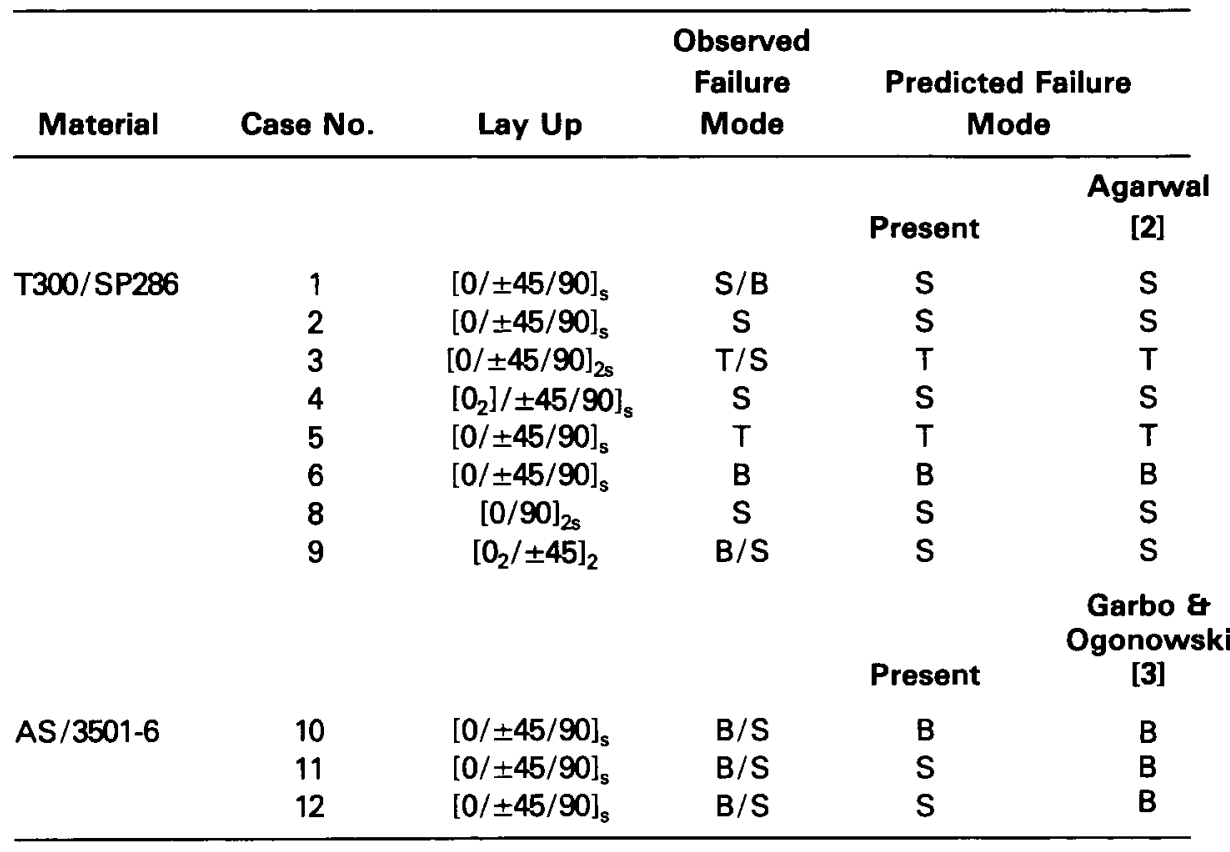

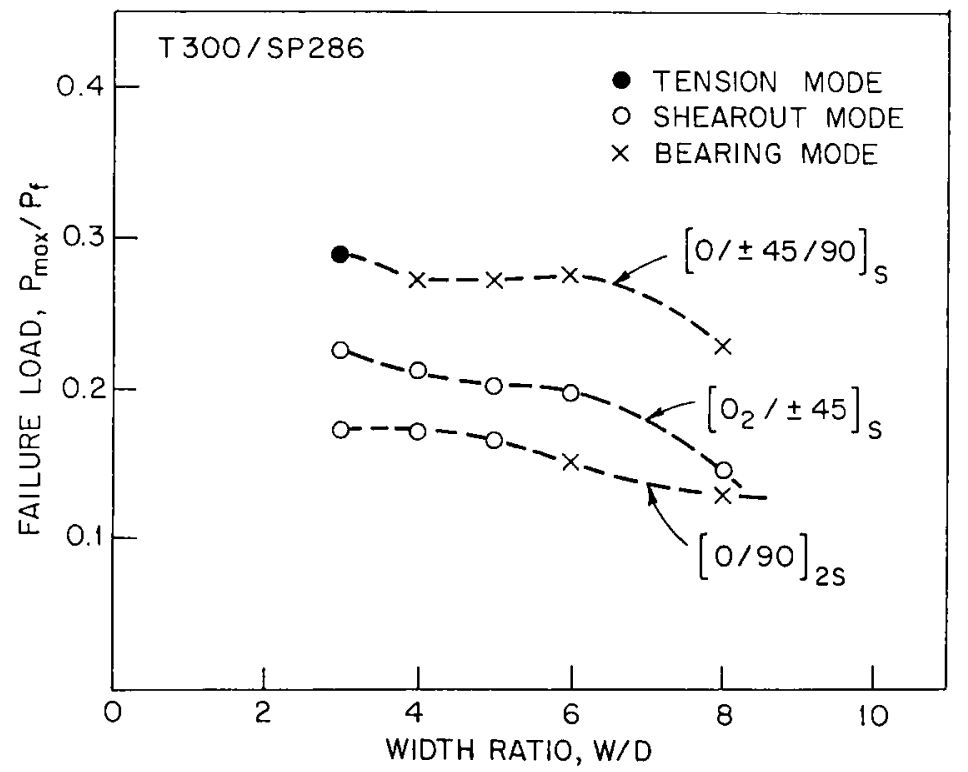

Figure 11. The Effects of Width Ratio on the Failure Load of Laminates with Different Ply Orientations. $P_{f}$ is the Tensile Failure Load of Laminates without Holes. Parameters used in the numerical Calculations: Material: Graphite/Epoxy T300/SP286, $W=38 \mathrm{~mm}, E=50.8 \mathrm{~mm}, L=203.2 \mathrm{~mm}$, $H=1.067 \mathrm{~mm}$, for $[0 / \pm 45 / 90]$, and $\left[0_{2} / \pm 45\right]$, and $H=1.118 \mathrm{~mm}$ for $[0 / 90]_{2 \mathrm{~s}}$. 
the strength reduces to zero $(P \rightarrow 0)$. Here failure loads were not calculated for $W / D$ less than three because at such low $W / D$ ratios the assumption of the cosine load distribution (eq. 17) is inaccurate [14].

The effect of edge distance $E$ on the failure load is shown in Figure 12. For the $[0 / \pm 45 / 90]_{s}$ and $[0 / 90]_{2 s}$ lay-ups increasng edge distance results in higher failure loads, as long as $E / D$ is less than about 4 . For higher edge ratios an increase in edge distance does not seem to influence significantly the failure load. For the lay-up $\left[0_{2} / \pm 45\right]_{s}$, the failure load does not vary significantly with $E / D$.

Effects of ply orientation on the failure load are given in Figure 13. This figure illustrates the effects of two parameters 1 ) the maximum ply angle $\phi$ in the laminate and 2) the change in orientation between two adjacent plies $\Delta \theta$. The latter parameter is referred to here as "ply continuity." The results in Figure 13 show that the failure load increases both with increasing $\phi$ and with increasing $\Delta \theta$, as long as failure is by shearout mode. On the other hand, the failure load decreases with increasing $\phi$ and with increasing $\Delta \theta$ when the failure is by tension mode. These results indicate that care must be exercised in designing bolted joints. If there are no other design constraints, the range of ply orientation $\phi$ and the ply continuity $\Delta \theta$ should be determined with the use of the computer code such that the joint can withstand the highest load.

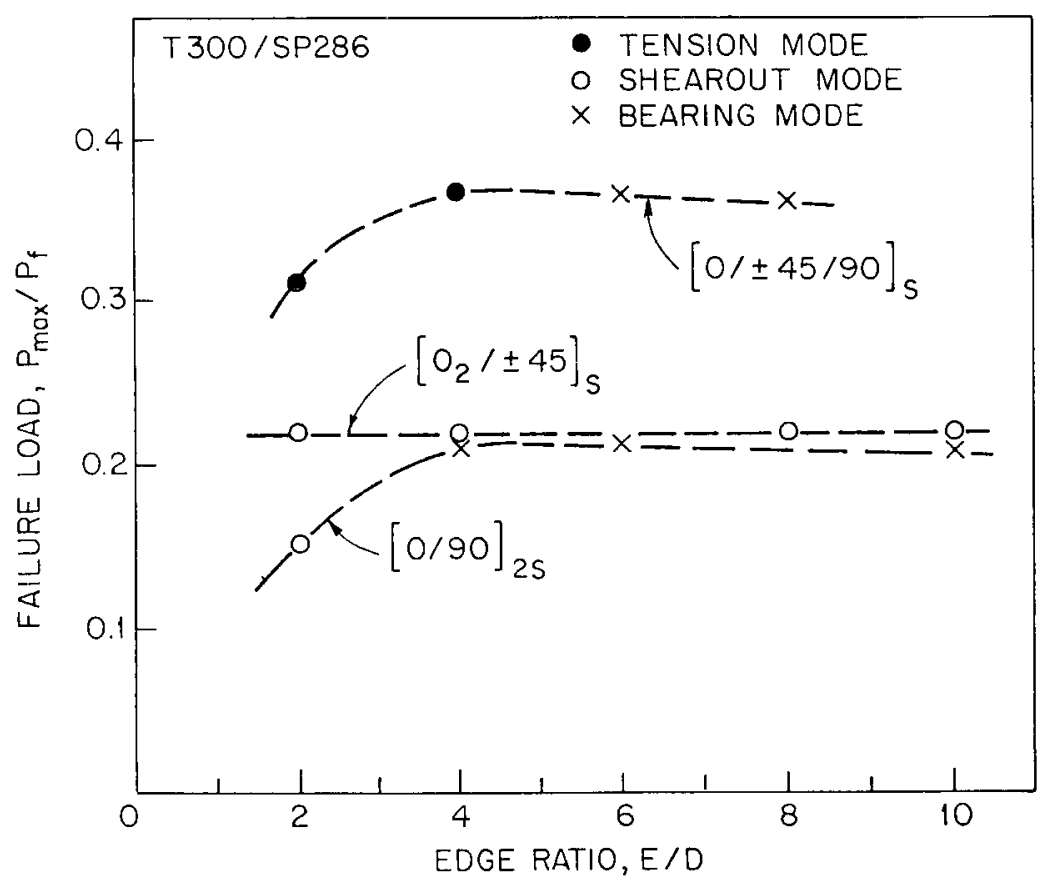

Figure 12. The Effects of Edge Ratio on the Failure Load of Laminates with Different Ply Orientations, $P_{f}$ is the Tensile Failure Load of Laminates Without Holes. Parameters Used in the Numerical Calculations: Material: Graphite/Epoxy T300/SP286, $D=5.08 \mathrm{~mm}, \mathrm{~W} / \mathrm{D}=5, L / D=14$. 


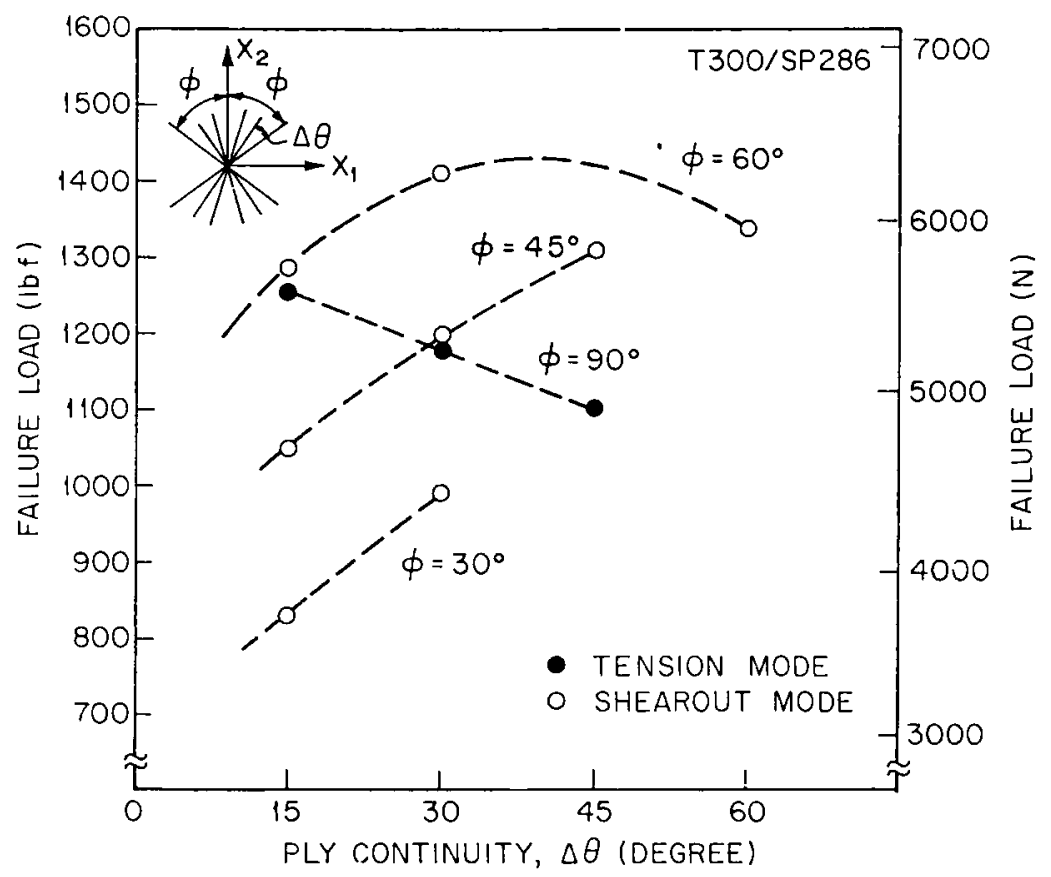

Figure 13. The Effects of Maximum Ply Angle $\phi$ and Ply Continuity $\Delta \theta$ on the Failure Load of Mechanically Fastened Joints. Parameters Used in the Numerical Calculations: Material: Graphite/Epoxy $T 300 / S P 286, \quad D=4.76 \mathrm{~mm}, W / D=5.336, \quad \mathrm{E} / \mathrm{D}=2.983, L / D=14.68$, $H=1.397 \mathrm{~mm}$.

\section{CONCLUDING REMARKS}

The model and computer code developed in this investigation can be used in the design of mechanically fastened joints involving fiber reinforced laminates. The computer code can be used to determine

a) the optimum geometry of a joint for a given load,

b) whether or not the joint will fail under a given load,

c) the failure load,

d) the mode of failure, and

e) the ply in which failure first occurs (regarded here as total failure).

The good accuracy of the method suggests that it might be worth it to extend the method to joints consisting of two or more fasteners.

The results of parametric studies performed with the present computer code show that the material properties, joint geometry, and ply orientation, all effect significantly the strength of mechanically fastened joints.

\section{ACKNOWLEDGEMENTS}

This work was supported by the Mechanics and Surface Interactions Branch, Nonmetallic Materials Division, Materials Laboratory, Air Force Wright 
Aeronautical Laboratories, Wright-Patterson AFB, Ohio. Dr. S. W. Tsai was the project engineer.

\section{REFERENCES}

1. Waszczak, J. P. and Cruse, T. A., "Failure Mode and Strength Predictions of Anisotropic Bolt Bearing Specimens," J. Composite Materials, Vol. 5, 1971, pp. 421-425.

2. Agarwal, B. L., "Static Strength Prediction of Bolted Joints in Composite Material," AIAA Journal, Vol. 18, 1980, pp. 1371-1375.

3. Garbo, S. P. and Ogonowski, J. M., "Effect of Variances and Manufacturing Tolerances on the Design Strength and Life of Mechanically Fastened Composite Joints," Flight Dynamics Laboratory, Air Force Wright Aeronautical Laboratories, Technical Report AFWAL-TR-313041, April 1981.

4. Wong, C. M. S. and Matthews, F. L., "A Finite Element Analysis of Single and Two-Hole Bolted Joints in Fibre Reinforced Plastic," J. Composite Materials, Vol. 16, 1982, pp. 481-491.

5. Rybicki, E. F. and Schmueser, D. W., "Effect of Stacking Sequence and Lay-Up Angle on Free Edge Stresses Around a Hole in a Laminated Plate under Tension,"'J. Composite Materials, Vol. 12, 1978, pp. 300-313.

6. Daniel, I. M., Rowlands, R. E., and Whiteside, J. B.,"Effects of Material and Stacking Sequence on Behavior of Composite Plates with Holes," Exp. Mech., Jan. 1974, pp. 1-9.

7. Whitney, J. M. and Kim, R. Y., "Effect of Stacking Sequence on the Notched Strength of Laminated Composites," Composite Materials: Testing and Design (Fourth Conference), ASTM STP 617, 1977, pp. 229-242.

8. Quinn, W. J. and Matthews, F. L., "The Effect of Stacking Sequence on the Pin-Bearing Strength in Glass Fibre Reinforced Plastic," J. Composite Materials, Vol. 11, 1977, pp. 139-145.

9. Yamada, S. E., "Analysis of Laminate Strength and Its Distribution," J. Composite Materials, Vol. 12, 1978, pp. 275-284.

10. Fung, Y. C., Foundation of Solid Mechanics, Prentice-Hall, Inc., Englewood Cliffs, New Jersey, 1965.

11. Jones, R. M., Mechanics of Composite Materials, Scripta Book Company, Washington, D.C., 1975.

12. Chang, F.-K., Scott, R. A. and Springer, G. S., "Strength of Mechanically Fastened Composite Joints," Air Force Wright Aeronautical Laboratories, Technical Report AFWAL-TR-82-4095 June, 1982.

13. Bickley, W., "The Distribution of Stress Round a Circular Hole in a Plate," Phil. Trans. Roy. Soc., A(London), Vol. 227, 1982, pp. 383-415.

14. De Jong, T., "Stress Around Pin-Loaded Holes in Elastically Orthotropic or Isotropic Plates," J. Composite Materials, Vol. 11, 1977, pp. 313-331.

15. Zienkiewicz, O. C., The Finite Element Method, McGraw-Hill Book Co., New York, 1977.

16. Whitney, J. M. and Nuismer, R. J., "Stress Fracture Criteria for Laminated Composite Containing Stress Concentrations," J. Composite Materials, Vol. 8, 1974, pp. 253-265.

17. Tsai, S. W., "Strength Theories of Filamentary Structures," in Fundamental Aspects of Fiber Reinforced Plastic Composites, R. T. Schwartz and H. S. Schwartz (eds.), Wiley Interscience, New York, 1968, pp. 3-11.

18. Tsai, S. W. and Wu, E. M., "A General Theory of Strength for Anisotropic Materials," J. Composite Materials, Vol. 5, 1971, pp. 58-80.

19. Tsai, S. W., "Mechanics of Composite Materials, Part II-Theoretical Aspects," Air Force Material Laboratory, Technical Report, AFML-TR-66-149, 1966.

20. Hoffman, O., "The Brittle Strength of Orthotropic Materials," J. Composite Materials, Vol 1, 1967, pp. 200-206. 
21. Nuismer, R. J. and Whitney, J. M., "Uniaxial Failure of Composite Laminates Containing Stress Concentrations," Fracture Mechanics of Composites, ASTM STP 593, 1975, pp. 117-142.

22. Timoshenko, S. and Woinowsky-Krieger, S., Theory of Plates and Shells, McGraw-Hill, New York, 1940.

23. Lekhnitskii, S. G., "Anisotropic Plates," (translated from the Second Russian Edition by S. W. Tsai and T. Cheron), Gordon and Breach, Science Publisher, Inc., New York, 1968.

24. Van Siclen, R. C., "Evaluation of Bolted Joints in Graphite/Epoxy," Proceedings of the Army Symposium on Solid Mechanics: Role of Mechanics in the Design of Structural Joints, 1974 pp. 120-138.

25. Hong, C.-S., "Stresses Around Pin-Loaded Hole in Finite Orthotropic Laminates," Transactions of the Japan Society for Composite Materials, Vol. 6, 1980, pp. 50-55.

26. Eshwar, V. A., Dattaguru, B., and Rao, A. K., "Partial Contact and Friction in Pin Joints," ARDB-STR-5010, India, 1977.

27. Nuismer, R. J. and Labor, J. D., "Applications of the Average Stress Failure Criterion: Part II-Compression," J. Composite Materials, Vol. 13, 1979, pp. 49-60. 